\title{
Prediction of Urban Growth through Cellular Automata-Markov Chain
}

\author{
Ahmadreza EBRAHIMIPOUR $^{1, *}$, Mehdi SAADAT $^{2}$, Amirreza FARSHCHIN $^{1}$ \\ *Corresponding author Email Address : ar_ebrahimipoor@yahoo.com \\ ${ }^{1}$ Faculty member at Academic Centre for Education, Culture and Research (ACECR) \\ ${ }^{2}$ Researcher
}

\begin{abstract}
Urban growth modelling can provide a useful tool to help decision-makers and urban planners evaluate different planning scenarios. Predicting the land uses and covers for sustainable utilization of lands cover is crucial due to rapid changes in the operations mainly arising from population growth and urbanization or perhaps because of changes in the stature of a city.

The application of urban growth models such as CA-Markov could raise awareness about the future growth of the city aimed at consciously controlling and changing the land use planning in the future.

The results of reviewing the urban growth process and land use changes around the city in the past mainly indicated the lands converted from agricultural use to urban areas across Bojnoord. Moreover, the hybrid model of CA-Markov was employed to predict the land use changes for the next 50 years with 10-year intervals between 2020 and 2070. The results showed that if the process of urban growth and land use changes in areas around the city persist, the urban areas will double by 2070 compared to 2009, while the agricultural lands will shrink to half. This could provide the context for environmental issues in the future. Hence, it is recommended that the inner capacity of the city be used instead of urban growth in the surrounding areas.
\end{abstract}

Keywords: urban growth, cellular automata-Markov chain model, sustainable urban development.

\section{Introduction}

The growing urbanization has been extremely accelerating due to migration to urban areas over the past decade. It is expected that the global urban population will reach 5 billion people by 2030 [1]. Understanding the mechanism of urban growth is vital in urban planning and management so as to achieve sustainable urban form. In this process, modeling tools can provide a helpful tool in planning and policy-making toward achievement of sustainable development [2]. Nowadays, remote sensing technologies and GIS as well as modeling and simulation provide an efficient tool in the service of urban management for detecting and predicting changes, measures and policies affecting the urban future growth planning. There are many strategies to model and predict changes in land cover and use, 
including statistical model, hybrid model, evolutionary model, system model and cellular model [3].

In recent decades, the modeling techniques have been expanded to simulate urban growth. In this respect, the CA model has been of interest to researchers owing to its simplicity, flexibility and ability to combine spatial and temporal dimensions. Despite simplicity, the CA is capable of simulating complex dynamic systems such as urban systems $[4,5]$. Each cell in land cover is more likely to change toward a class located in its proximity. This phenomenon can be modeled using CA [6]. According to various studies, the cellular automata model is a useful tool for modeling urban changes, applicable in various topics such as urban growth predicting, simulation of traffic, land use and land cover changes $[2,6]$.

Markov chain is a series of random values whose likelihood of occurrence in a given time interval is dependent on the values of the past. As a stochastic model, the Markov model is able to analyse the land cover and use images related to two time periods, so as to generate the transition probability matrix $[7,8]$.

The capability of hybrid CA-Markov model has been widely employed in predicting changes in land use and land cover. In this hybrid model, Markov chain generates the transition probability matrix while the cellular automata control the evolution and changes in the cells [9, 10 and 11].

Cellular automata model was first proposed in the 1940s and 1950s by two mathematicians called Olam and Neumann so as to simulate complex systems in physics and biology. Due to lack of computing capacity up to 1970s, however, few researchers employed the model until 1970, when John Horton developed its famous Game of Life model, followed by researchers from other fields utilizing the model. Nonetheless, Toiler was the first researcher who modelled the cellular space through a definition of cellular geography which involved the field of urban studies. This model comprises several elements including network, cell state, neighbourhood, transition and time rules. The cellular automata mainly refers to a type of CA model outlining its networks and neighborhoods on the twodimensional plane $[2,4]$. The concept of time within the cellular automata is discrete. The interval phase in cellular automata models may vary. The longer the interval the more discrete the CA and vice versa. At intervals $\mathrm{T}$ and $\mathrm{T}+1$, the cells in cellular automata model will obtain different modes. Hence, $\mathrm{T}$ to $\mathrm{T}+1$ represents the evolution of cellular automata. Therefore, the CA modeling techniques can be adopted to simulate dynamic systems or generate the organized patterns throughout the evolution (from $\mathrm{T}$ to $\mathrm{T}+1$ ). The most famous urban CA model has developed based on two-dimensional CA [2].

The Markov chain is a specific form of more general possibility models known as random processes where the current state of a system depends to a previous state. In other words, it involves a series of random values to which the probabilities depend within an interval in the past. Markov is employed as a stochastic model analysing the pair of images for land use and land cover, generating a transition probability matrix. In theory, a land use 
may over time change to another use. The Markov analysis adopts matrices depicting all land-use changes among all groups of land use [12].

Executive experience and studies demonstrated that many urban studies explored the process of urban growth using GIS and predictive models in different countries, including in Iran noted below.

In a study titled "Evaluation of the process of urban growth and determining the appropriate urban area of future growth", Ahmadreza Ebrahimipour explored the urban growth in Bojnoord using aerial photographs and satellite images captured between 1956 and 2009. This study focused on the damage to the environment mainly due to the destruction of farm lands surrounding the city. In addition, the zones prone to damage such as floods and earthquakes were detected. The results showed that urban growth across Bojnoord resembled many cities in Iran over the last six decades without any planning and consideration. The only determinant of urban growth was proximity to areas previously built and natural obstacles to construction [13].

In a study titled "urban growth modeling in Tehran, using CA-Markov", Mohammad Mehdi Khoshgoftar and Mohammad Talei examined and modeled the urban development of Tehran in the past two decades. In this study, the process of urban growth was explored through historical data obtained by Landsat satellite images related to 1988, 2000 and 2006, where the simulation extended to 2025. Comparison of changes between 1988 and 2006 showed that urban areas expanded by about $11 \%$. The results showed that the hybrid CA-Markov model performed greatly in predicting urban growth for the coming years based on the growth pattern of previous years [14].

In a study titled "A cellular automata, new method for simulating urban growth", Rezazadeh and Razieh Mirahmadi Mehrdad described the cellular automata model and its application in the simulation of urban growth. They introduced the principles and constituent elements as well as how the cellular automata model simulates the urban growth. The aim of this study was to identify the cellular automata model and how to use it in urban studies, ultimately proposing a framework for designing an urban cellular automata model so that researchers can model the urban phenomena through the new approach [2].

In a study titled "Analysis of urban growth orientation using GIS techniques in the metro bulletin region of Mumbai, India“", Kumar phatuk et al. considered the land capacity factors based on population. The results of this study indicated that the general methods of analysis in GIS based on time series data on urban physical expansion as well as satellite images to predict the orientation of population to urban sprawl given the capacity of the land can be used as effective tools [15].

In a study titled "Cellular automata modeling tools - GIS for urban planning and decision-making“, D. Stevens et al. examined the cellular automata method for modeling the urban physical development. In this study, the author tried to make changes in cellular automata to provide a proper model to simulate urban growth. The results indicated that better results in terms of urban growth modeling can be achieved by a series of changes in cellular automata [16]. 
QIONG et al conducted a research tiled "review and prediction of urban land uses in Beijing using satellite imagery and GIS“, where the land use changes in the time period between 1986 and 2001 were analysed. The results showed an uneven growth during this period, when most urban growth and destruction of agricultural land had happened in the suburbs. In addition, the Markov chain model and regression have been employed to change land use for the next 20 years. The results of this study showed that GIS and remote sensing technology along with Markov Chain model and regression can be considered as an effective tool for predicting urban growth [17].

In a study titled "Modeling of Urban Growth in Atlanta using Logistic Regression", ZHIYONG et al. modeled the urban growth in GIS environments of Atlanta. In this study, the historical data on land use and cover images were extracted from TM 1987 and 1997 using two factors of population density and distance for modeling the urban growth through logistic regression. The results showed a high correlation between urban growth and transport network [18].

In their study titled "Development of dynamic modeling TAMPA Bay using parallel computing“, George Xian et al. (2007) modeled the urban development. This study involved a model of urban growth called SLEUTH with six parameters (slope, land use, transportation, city limits, restrictions, and altitude). The process of urbanization and land use changes were evaluated for TAMPA BAY from 1992 to 2025. The results showed that urbanization left dramatic changes in the landscape and ecosystem of the area in a way that urbanization by 2025 will destruct agricultural land and forests respectively by 58 and $80 \%$, expanding the urban boundaries twofold [19].

In a study titled "Urban Development Simulation using Kernel-based Cellular Automata", Xiaoping Liu et al. (2008) explored the cellular automata on urban development. It was revealed that information about the process of urban growth in the past can be employed similar to traditional realist urban patterns to calibrate the cellular automata models. The aim of this research was to utilize the kernel-based techniques to discover linear transformation rules for cellular automata. The results of this study to simulate urban expansion in China's fast-growing Guangzhoa demonstrated that the kernel-based cellular automata was more accurate than cellular automata based on natural network. Generally, the cellular automata have been on a growing trend for simulation of complex urban system [20].

Using the Markov model and Cellular Automata filter, Ayodeiji Opeyemi examined the cover and land use changes area in Karara and predicted changes in the next 14 years. The results showed the rapid growth of residential uses due to the physical growth of the city [21].

Other studies have suggested that planning for the city's growth is crucial. If planning is not done in this field, there would be numerous problems for the environment and citizens, putting them to all kinds of threats and vulnerabilities. Nonetheless, the simulation models and urban growth have prompted the managers and decision-makers to deal with the threats and vulnerabilities, helping them to achieve a sustainable urban development. 
Meantime, the results showed the effectiveness and capability of cellular automata as well as hybrid model cellular automata-Markov for predicting the future growth of the city.

The results also indicated the high efficiency of cellular automata-Markov chain model in the reviewing process of urban growth and predicting its future. Hence, it is essential to employ this mode to realize the sustainable urban growth.

\subsection{Area under study:}

Bojnourd is the city center of North Khorasan province stretching at $37^{\circ} 28^{\prime}$ latitude and $57^{\circ} 20^{\prime}$ longitude with a height from sea level of $1,010 \mathrm{~m}$. It is located within a plain about a hundred square kilometers surrounded on all sides by mountains(fig.1).

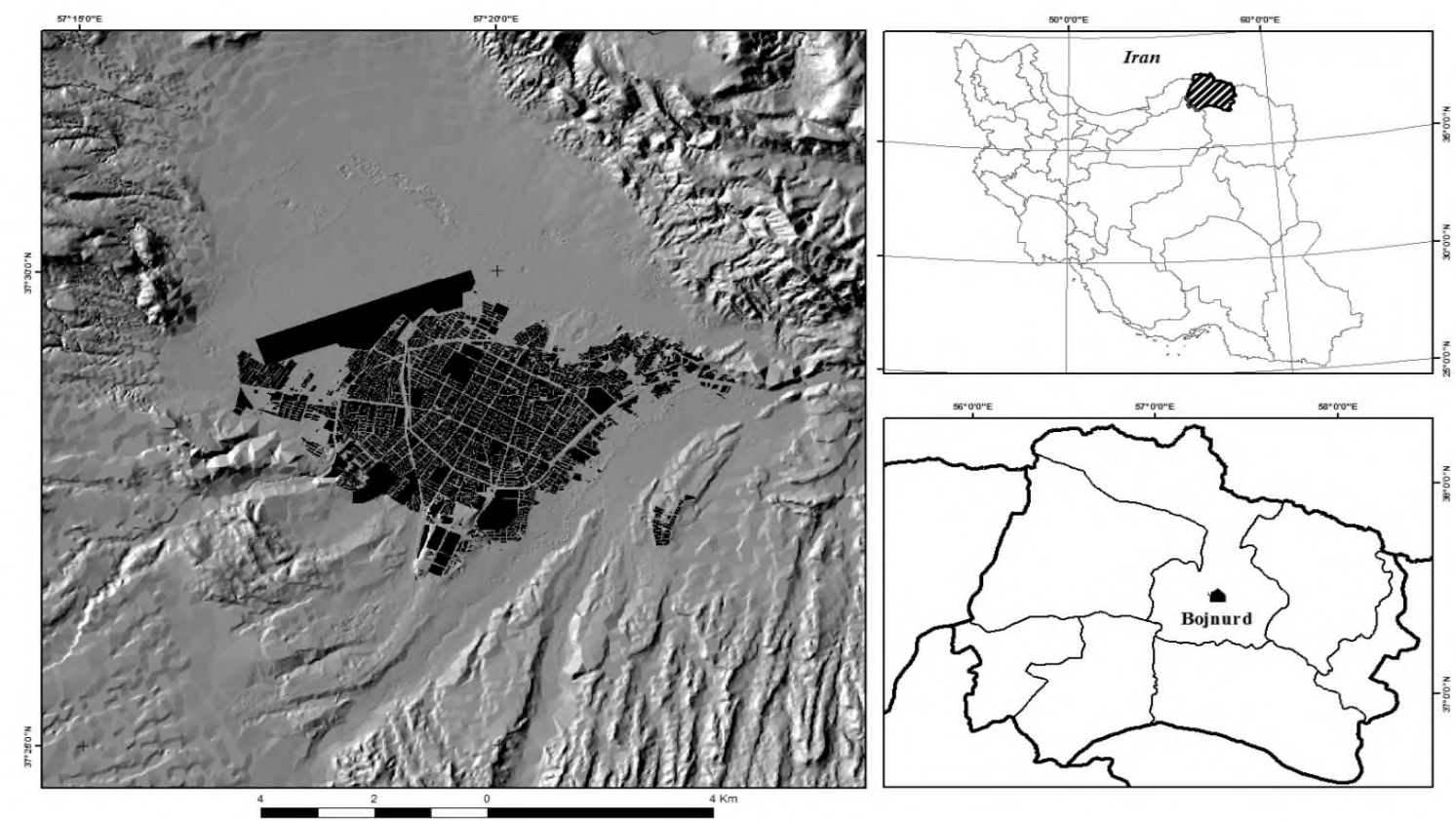

Fig. 1 : Location of the study area

About 300 years ago, the nucleus of the present city of Bojnoord was founded while there were no major natural physical features. In the wake of economic and social developments of the last century and the subsequent increase in population, the relatively dense texture of the city began to expand in almost all directions over the last two decades. The urban sprawl on farm land is a reality found in every Iranian city, whose buildingblock has been founded in the heart of plains. Because of the low cost of construction of buildings and development of communication network in such areas, maximum construction and development measures have taken place. 


\section{Materials}

\section{Aerial photographs, satellite images and base maps}

In order to study the growth trend in Bojnoord and its environmental impact, large-scale aerial photographs and satellite images were employed at high geometric accuracy. The first aerial photography coverage throughout the country, where Bojnoord was included, dates back to 1956, prior to which there are no aerial images available. Due to lack of access to reliable sources of information (aerial photos or map) prior to 1956, the growth of Bojnourd was evaluated for that date onwards.

Aerial photographs and satellite images used in this project involved those aerial photos captured across the country in 1956.1964, 1978 and 1994. The satellite images contain pictures taken by Quick satellite in 2004 and 2009.

Although the satellite images used in this study are of higher quality than the aerial photos, there was no access to these images in previous years, because the high-quality satellites have been launched only in the past two decades. Therefore, urban growth was studied base on aerial photos captured between 1956 and 1978, while the satellite images replaced aerial photos for 2004 and 2009. In addition to aerial photographs and satellite images of topographic maps with a scale of 1:2000 and 1:25000, the map of underground water, soil classification for extraction of data layers were used to produce the desirable maps.

\section{Results:}

\subsection{Extraction of land use maps}

In the first phase, land use maps from aerial photographs and satellite images were extracted. Due to the use of satellite imagery with high spatial resolution $(60 \mathrm{~cm})$ and large-scale aerial photos of the area instead of using computer classification methods, the visual technique was employed extract the land use map. In this regard, the land use map (fig. 2) was prepared for the six time periods (1956, 1964, 1978, 1994 and 2009), each entailing three types of maps including uncultivated, agricultural and built (urban areas, military, industrial). Since the inputs were rasterized, the land use map were converted from vector to raster format. 


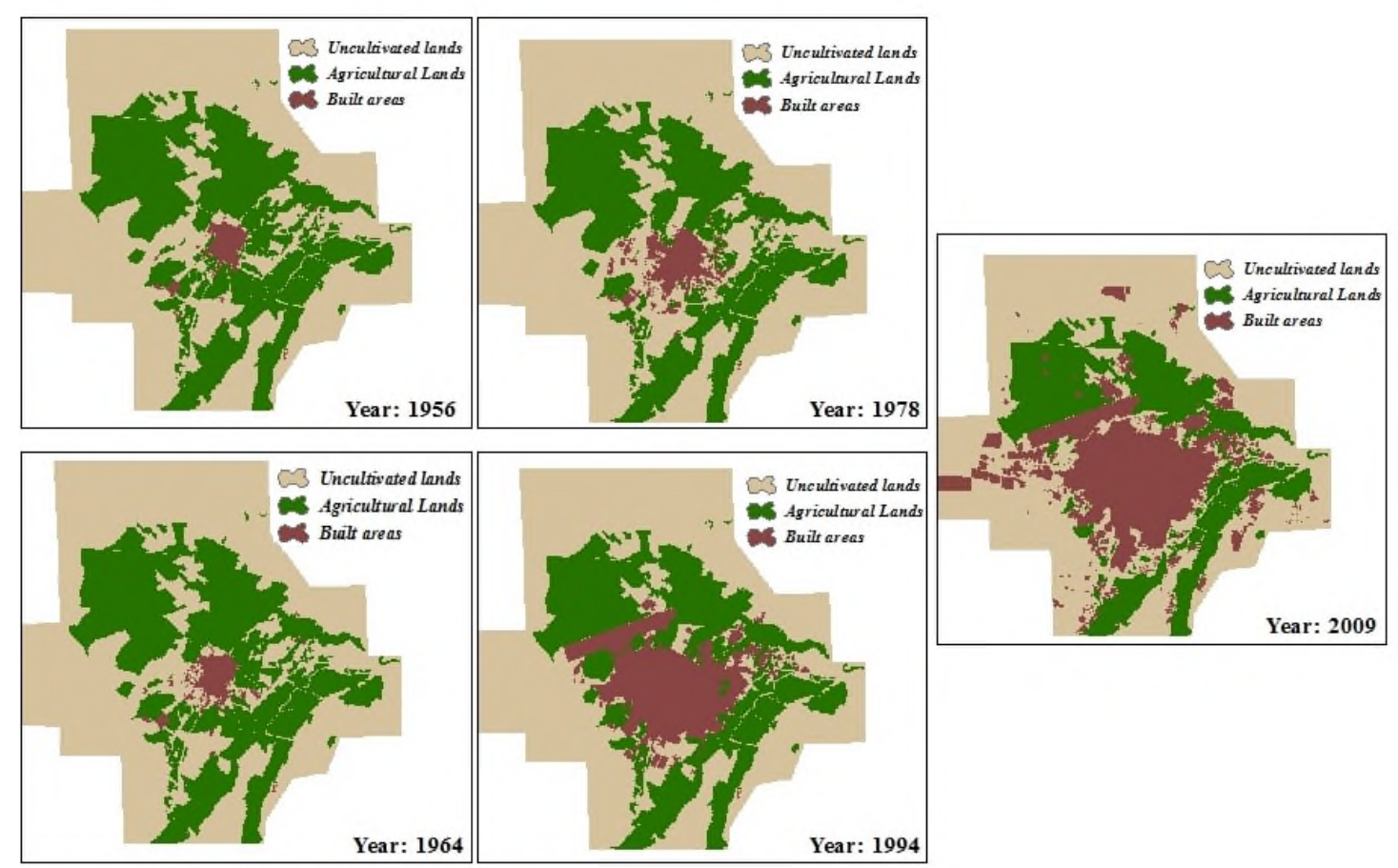

Fig. 2 : Land use map for 1956, 1964, 1978, 1994 and 2009

\subsection{Land use changes between 1956 and 2009}

The overview of changes in land use between 1956 and 2009 showed an increase of built areas and correspondingly reduction in the uncultivated and agricultural lands. In fact, the largest percentage of changes in each period compared to the previous one can be found in the built areas. As shown in Figure 2 and 3, the trend of changes was not consistent in all periods, but escalated from 1978 onwards with the maximum points found during 1978 to 1994. Studies show the severity of these changes reduced in the next few years.

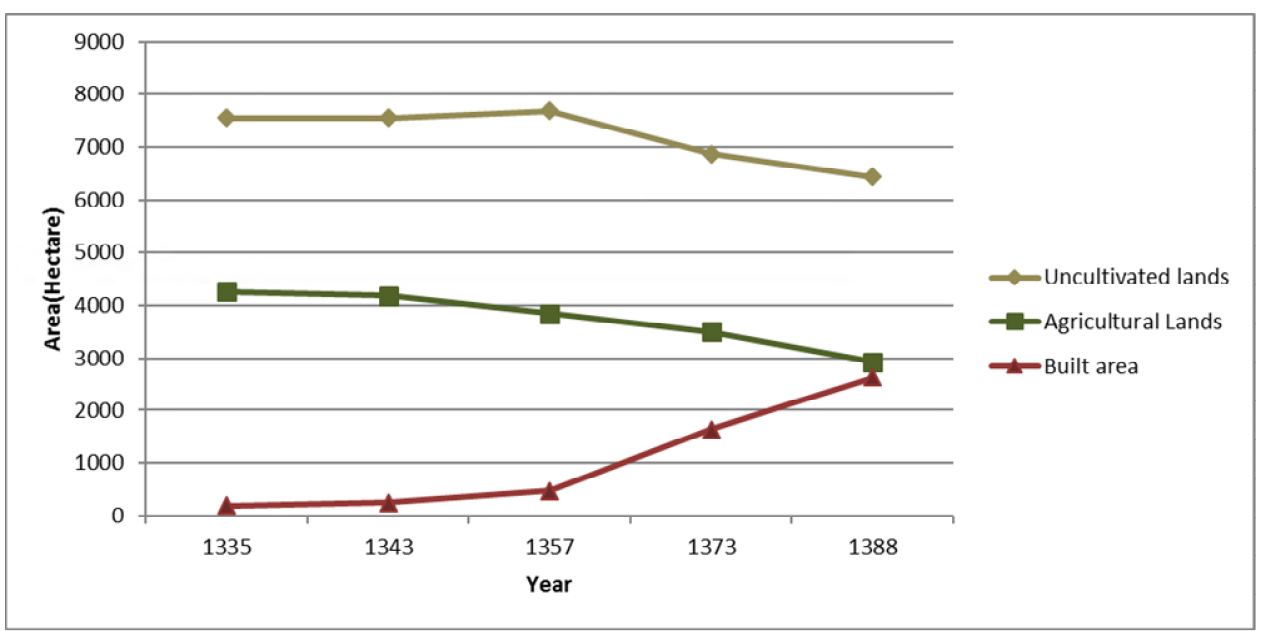

Fig. 3: The trend of changes in land use between 1956 and 2009 


\subsection{Predicted trends in land use and urban growth between 2009 and 2070}

\subsubsection{Compilation of suitability maps}

The first step in predicting changes in land use and urban growth is to produce suitability maps. Therefore, the suitability maps in this study were produced for agricultural and built uses through multi-criteria analysis models. To this end, the required maps as the criteria of suitability maps were extracted from satellite images and aerial photographs, base maps, including urban maps of 1:2000, topographic maps of 1:25000 and 1:2000. (Table 1 and 4)

The map of agricultural and uncultivated land and road network map were extracted from satellite images aerial photos over various years. The gradient map was extracted from digital elevation model (DEM) prepared based on topographic maps with a scale of 1:25000 and 1:2000. The topographic maps were adopted at different scales because the maps of 1:2000 did not cover the entire area under study, and only the surroundings had the scale. The entire area was therefore covered by maps of 1:2000 together with topographic maps of 1:25,000.

Since the gradient maps used in production of suitability maps for agriculture and built areas varied, there were two different gradient maps produced under different classifications. Once gradient map and classification on the basis of urban planning standards (Table 2), and once based on the standards defined in agriculture (Table 4).

The maps of flood-risk areas acting as a barrier to the urban growth were also prepared. In preparing the watercourse zoning map, it was impossible to adopt specialized models such as (HEC_RAS) due to lack of information on the input parameters. For this reason, the latitudinal profile was drawn on the regional DEM to depict the three hazard zones due to proximity to the watercourse.

The classification maps of soil and depth of groundwater were used as inclusion criteria to produce the potential agricultural areas.

Restrictions map, including the built areas, roads and watercourse network extracted from satellite images.

In this study, the suitability maps were produced through the mean weighted linear combination (WLC).

Table 1: Standard maps for the production of suitability map for built areas.

\begin{tabular}{cl}
\hline Nature & \multicolumn{1}{c}{ Standard maps } \\
\hline \hline Continuous & Uncultivated and agricultural lands map \\
Continuous & Distance from downtown map \\
Continuous & Map of areas built \\
Continuous & Distance from communication roads \\
Continuous & Gradient map \\
Continuous & Watercourse zoning map \\
Discrete & Restrictions map \\
\hline
\end{tabular}


Table 2: Classification of gradients for the production of suitability maps

\begin{tabular}{cc}
\multicolumn{2}{c}{ for the built areas. } \\
\hline Degree of importance & \multicolumn{1}{c}{ Classification of gradients (degree) } \\
\hline Minimum & $0-3$ \\
Maximum & $3-15$ \\
Minimum & Gradients greater than 15 \\
\hline \hline
\end{tabular}

Table 3: Standard maps for the production of suitability maps for agricultural lands

\begin{tabular}{cl}
\hline Nature & \multicolumn{1}{c}{ Standard maps } \\
\hline \hline Continuous & Uncultivated and agricultural lands map \\
Continuous & Soil classification map \\
Continuous & Groundwater depth map \\
Continuous & Gradient map \\
Discrete & Restriction maps \\
\hline
\end{tabular}

Table 4: Classification of gradients for the production of suitability maps for the agricultural areas

\begin{tabular}{cc}
\hline Degree of importance & Classification of gradients (degree) \\
\hline \hline 6 & $0-2$ \\
5 & $2-4$ \\
4 & $4-8$ \\
3 & $8-16$ \\
2 & $16-32$ \\
1 & Gradients greater than 32 \\
\hline
\end{tabular}

\subsubsection{Weighting of criteria}

Analytical hierarchy process (AHP) is one of the most popular multipurpose decisionmaking techniques first invented by Thomas. L. Saaty in the 1970s. This technique can be adopted when it comes to decisions or several competing options ahead. These criteria can be either qualitative or quantitative. This decision-making method is based on paired comparisons. The decision-maker begins by providing a decision tree hierarchy. The decision tree hierarchy depicts the factors compared and evaluates the competing alternatives. Then a series of paired comparisons are made. These comparisons outline the weight of each factor in order to determine the competing options. Finally, the AHP logic integrates the matrices of pairwise comparison in a way that the optimal decision is achieved [12]. In this study, the criteria were weighted through the AHP (Tables 5 and 6). 
Table 5: The weights extracted from the AHP method to produce suitability maps for the built areas

\begin{tabular}{cl}
\hline \hline Weight & \multicolumn{1}{c}{ Standard maps } \\
\hline 0.0694 & Uncultivated and agricultural lands map \\
0.1627 & Distance from downtown map \\
0.3743 & Map of areas built \\
0.2561 & Distance from communication roads \\
0.0379 & Gradient map \\
0.0997 & Watercourse zoning map \\
0.02 & Consistency ratio \\
\hline
\end{tabular}

Table 6: The weights extracted from the AHP method to produce suitability maps for the agricultural areas

\begin{tabular}{cl}
\hline Weight & \multicolumn{1}{c}{ Standard maps } \\
\hline \hline 0.2839 & Uncultivated and agricultural lands map \\
0.5183 & Soil classification map \\
0.0989 & Groundwater depth map \\
0.0989 & Gradient map \\
0.00 & Consistency ratio \\
\hline
\end{tabular}

Source: Author's calculations

\subsubsection{Overlapping of suitability maps on satellite images}

At this stage, the suitability maps through the multi-criteria analysis were better assessed by integrating the maps on satellite images of 2009. As indicated in agricultural potential map (Fig. 4), nearly all lands currently considered to be part of the agricultural land enjoyed great agricultural potential.

There is no potential for urban growth in the potential map of built areas (Fig. 4) which is similar to agricultural potential map as an outcome of the multi-criteria model demonstrates the urban growth obstacles (valley and flood risk) in the eastern region. Generally, most parts of the region except for the North-West with high potential agricultural areas, the other areas entail no suitable potentials for agriculture. 


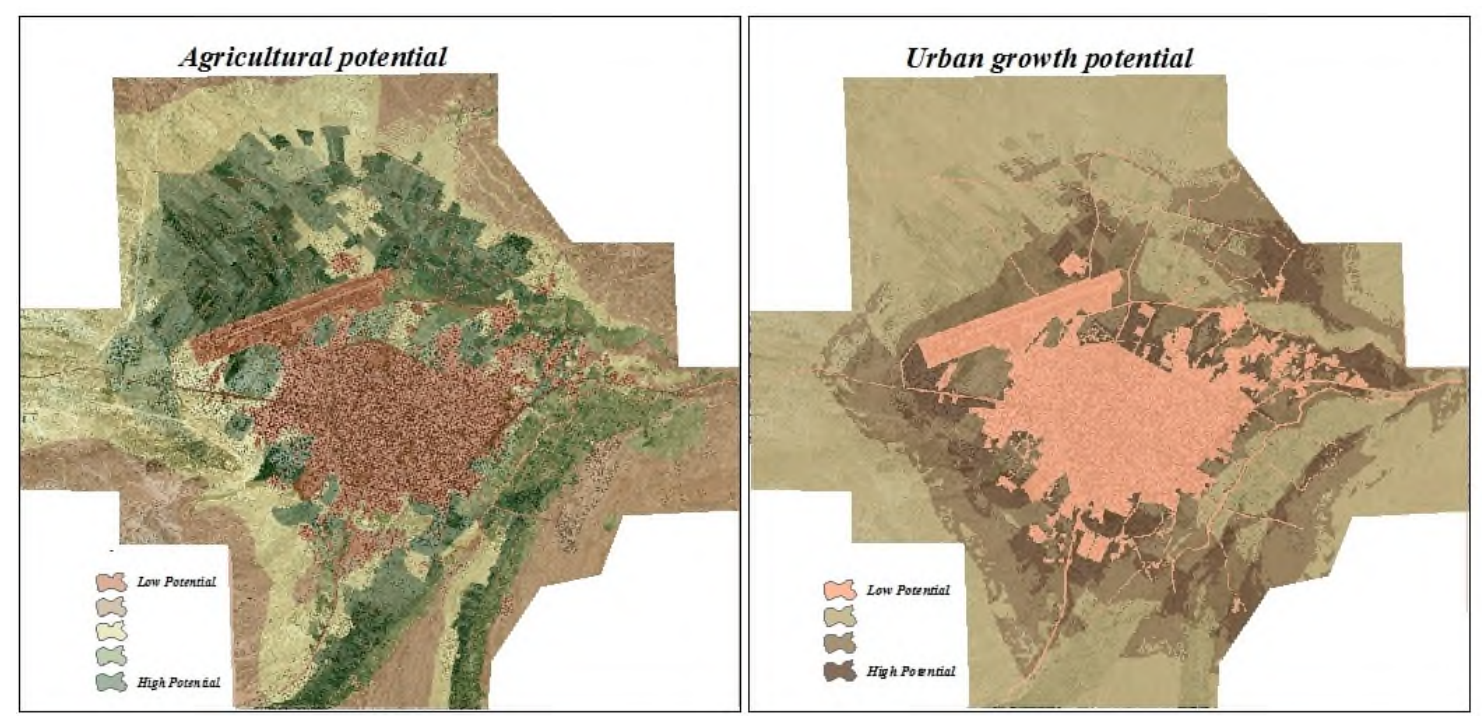

Fig. 4: Agricultural potential map and Map of potential built areas

\subsubsection{Assessment of suitability maps}

\subsubsection{Agricultural suitability map}

As seen in Figure 4, lands with higher potential are mainly concentrated around the city because the urban growth has destroyed the agricultural land over many years, turning them into the built areas. As mentioned earlier, new lands for agriculture were replaced in any era by destroying the agricultural lands around the city. As can be seen in the map, however, the agricultural lands have extended to the cultivation areas today. In case the urban development penetrates these lands, there will not be any replacement to the agricultural lands. The overview of agricultural potential map indicated that these areas are concentrated mainly in two parts.

1. Relatively shallow valleys that extend along the eastern axis of the city, which has not been transgressed due to the risk of flood runoff and part of the urban development in the eastern part of town over recent as extended on the other side of the valley. Actually, the latest satellite images show fairly wide activities to promote the construction of settlements in the north. Given that these areas have no potential for agriculture, any urban development in this area would practically prevent the degradation of agricultural lands in other places. There is hope for urban development in this area. It might be argued that urban development has occurred randomly in the area, or rather based on a plan devised by urban managers for controlled urban development aimed at preventing any violent growth. 2. North and North-West of Bojnoord

This area is more extensive than the previous area. Owing to its perfect gradient and smooth surface, it can be more susceptible to construction. At the moment, however, man- 
made and natural obstacles can hinder the violent urban growth in the future. This can be an obstacle against any transgression to agricultural lands in the northern region due to topography (valleys) and airport in the North West. So long as land uses are not modified, they can prevent any violent urban growth in the region.

\subsubsection{Suitability map of built areas}

Naturally, urban growth will occur in areas adjacent to the existing built areas, where construction easily takes place. In general, there are two factors hindering the urban growth in some areas. As seen in Figure 4, the natural barrier in the East (low altitude and high risk of flooding) prevented the area to gain a great potential for urban growth. In addition to the natural barriers, human intervention and planning in the future growth of cities can inhibit the growth of the city in some areas. Since the urban growth potential map was derived from a multi-criteria model where the sustainable urban development serves to prevent the destruction of agricultural lands, there are areas with great growth potentials never overlapping with areas suitable for agriculture or high-risk areas.

\subsubsection{Calculation of Markov transition matrix}

The transition probability matrix is calculated by Markov Chain Model, which represents the probability of each land use change to another within a new period compared to the previous one:

The Markov transition matrix was calculated in each period through the use map for the beginning and end of the period. In fact, the land uses were compared pairwise so as to calculate the transition probability of land uses to one another. The outputs of this matrix (Tables 7 to 10) show the transition probability of land use.

Table 7: Markov transition probability matrix in the period 1956-1964

\begin{tabular}{llll}
\hline \multirow{2}{*}{1956} & $\begin{array}{l}\text { Uncultivated } \\
\text { lands }\end{array}$ & Agricultural lands & Built lands \\
\hline \hline Uncultivated lands & 0.9876 & 0.0019 & 0.0105 \\
Agricultural lands & 0.0259 & 0.9690 & 0.0051 \\
Built lands & 0.0000 & 0.0000 & 1.0000 \\
\hline
\end{tabular}

Table 8: Markov probability matrix conversion in the period 1964-1978

\begin{tabular}{|c|c|c|c|c|}
\hline 1964 & 1978 & $\begin{array}{l}\text { Uncultivated } \\
\text { lands }\end{array}$ & Agricultural lands & Built lands \\
\hline Uncultivated lands & & 0.9743 & 0.0035 & 0.0222 \\
\hline Agricultural lands & & 0.0798 & 0.8977 & 0.0226 \\
\hline Built lands & & 0.0191 & 0.0425 & 0.9384 \\
\hline
\end{tabular}


Bulletin de la Société Royale des Sciences de Liège, Vol. 85, 2016, p. 824 - 839

Table 9: Markov transition probability matrix in the period 1978-1994

\begin{tabular}{|c|c|c|c|c|}
\hline 1978 & 1994 & $\begin{array}{l}\text { Uncultivated } \\
\text { lands }\end{array}$ & Agricultural lands & Built lands \\
\hline Uncultivated lands & & 0.8999 & 0.0000 & 0.1001 \\
\hline Agricultural lands & & 0.0000 & 0.9152 & 0.0848 \\
\hline Built lands & & 0.0031 & 0.0000 & 0.9969 \\
\hline
\end{tabular}

Table 10: Markov transition probability matrix in the period 1994-2009

\begin{tabular}{llll}
\hline \multirow{2}{*}{2009} & $\begin{array}{l}\text { Uncultivated } \\
\text { lands }\end{array}$ & Agricultural lands & Built lands \\
\hline \hline Uncultivated lands & 0.9030 & 0.0035 & 0.0935 \\
Agricultural lands & 0.0930 & 0.8600 & 0.0470 \\
Built lands & 0.0023 & 0.0002 & 0.9975 \\
\hline
\end{tabular}

Land use maps produced for the years 2020 to 2070

In the last stage of the research, the land use map for the years 2020 to 2070 was produced at ten-year intervals. Given that the transition probability matrix generated by the Markov model actually forms the basis of the CA-Markov prediction model, it can create the transition probability matrix as a stochastic model through the pairwise analysis of land use and cover images.

The transition probability matrix was used to predict the uses in different years because the intensities of land use change were identical in all the years (Fig. 5). 


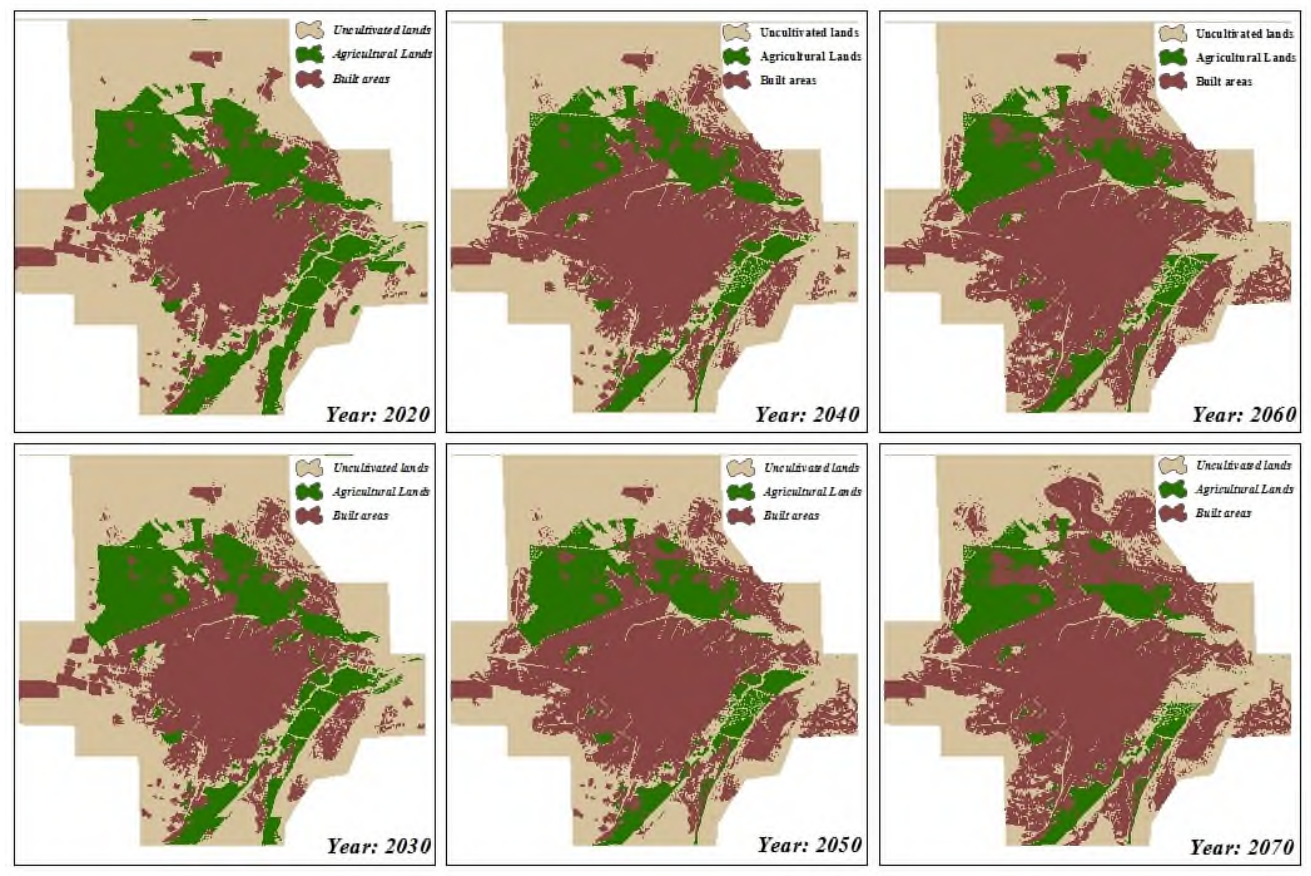

Fig. 5: Prediction of land use changes between 2020 and 2070

\section{Conclusions:}

The application of temporal-spatial data on exploring the changes and how they occurred in the past and simulate future land use and cover can help managers and decision-makers to review the different scenarios and select the best and most appropriate options. It could also provide the grounds for sustainable urban development.

Nonetheless, the pattern of land use and land cover in each region are an outcome of environmental, economic and social conditions governing the area. The passage of time might alter the governing conditions and consequently evolve the land uses. When predictive models are adopted to figure out the trends and rates of land use change in the future, it is essential to consider the changes in conditions affected by the economic, social and environmental factors. Otherwise, the results of the model cannot be close to reality.

The CA-Markov model predicts changes based on the assumption that the trend and pace of changes are similar in the future, past and present. If predictions are made closer to reality, there will be similar conditions and trends in the future as in the past and present. The detection of changes in different land uses in the future can help managers and policymakers make informed decisions and maintain sustainable resources. In this light, the trend of future changes can be simulated in different conditions. Moreover, the feedback from each type of change in the contributing factors can be identified, making great efforts to control the conditions and factors in a way that land use change in the future will be based on sustainable development. Therefore, the data obtained from the change probability matrix (using the Markov model) as well as the spatial distribution of changes in each of 
land uses (using the CA-Markov model) can be adopted to devise appropriate management strategies, so as to put an end to the unfavorable trends of land use change and take effective steps to control the inappropriate changes. The results revealed the need to implement such management practices to control the physical development of the city given the vulnerability of unplanned growth.

If this strategy carries on the current land use regardless of sustainable urban development, there will certainly be many challenges in the future.

The urban growth was persistent in the period between 1956 and 2009. This can to some extent slow down the urban growth trend, even though construction of a residential complex in the north of the city apart from the current texture of the city will enhance the urban growth.

Given that the prediction of land use changes for the coming years was based on the period 1994 to 2009, the simulation will be consistent with reality when the conditions and factors contributing to the land use change are identical in the future.

The results of the new model indicated that land use change generally progress from agricultural to uncultivated areas. In case such trend persists over the next fifty years, a major portion of farms will be destroyed and the region might face environmental problems, which are at odds with sustainable urban development.

\section{References}

1. Han J, Hayashi Y, Cao X, Imura H. Application of an integrated system dynamics and cellular automata model for urban growth assessment: A case study of Shanghai, China. Landscape and Urban Planning. 2009;91(3):133-41.

2. Rezazadeh R, Mirahmadi M. A Cellular Automata is a new method to simulate urban growth. Journal of Educational Technology. 2009;4.

3. Parker, DC., Manson, SM., Janssen, MA., Hoffmann, MJ., Deadman, P., Malti agent systems for the simulation of land use and land cover change: a Review. Annals of the Association of American Geographers, 93(2), 314-337.

4. Santé I, García AM, Miranda D, Crecente R. Cellular automata models for the simulation of real-world urban processes: A review and analysis. Landscape and Urban Planning. 2010;96(2):108-22.

5. Chen Y, Li X, Liu X, Ai B, Li S. Capturing the varying effects of driving forces over time for the simulation of urban growth by using survival analysis and cellular automata. Landscape and Urban Planning. 2016;152:59-71.

6. Ward DP, Murray AT, Phinn SR. A stochastically constrained cellular model of urban growth. Computers, Environment and Urban Systems. 2000;24(6):539-58.

7. Halmy MWA, Gessler PE, Hicke JA, Salem BB. Land use/land cover change detection and prediction in the north-western coastal desert of Egypt using Markov-CA. Applied Geography. 2015;63:101-12. 
8. Kaveh N, Ebrahimi a. Prediction of land use / cover changes Using CA- Markov model. Journal of applied remote sensing and gis in natural resource. 2013;2.

9. Ayodeji, Opeyemi Z., 2006. Change detection in land use and land cover using remote sensing data and GIS (A case study of Ilorin and its environs in Kwara State). The department of Geography, University of Ibadan in Partial Fulfilment for the award of master of science, pp. 44

10. Chang, CL., Chang, JC., 2006. Markov model and cellular automata for vegetation. Journal of Geographical Research 45: 45-57.

11. Kamusoko C, Aniya M, Adi B, Manjoro M. Rural sustainability under threat in Zimbabwe - Simulation of future land use/cover changes in the Bindura district based on the Markov-cellular automata model. Applied Geography. 2009;29(3):435-47.

12. Muller, MR., Middleton, J., 1994. A Markov model of land-use change dynamics in the Niagara Region, Ontario, Canada. Landscape Ecology, 9(2): 151-157.

13. Ebrahimipoor A, saadat m. Evaluation of urban growth Assessment of urban growth trends and determine the suitable zone of future growth in 1956-2009 Case Study Bojnoord Proceedings of the Third International Conference of Civil Engineering, Architecture and Urban Management. 2016.

14. Khoshgoftar M, Taleei. simulation of urban growth in Tehran using CA - Markov model. Journal of Remote Sensing and GIS. 2010;2(2).

15. Manish, KUMAR., D. K. TRIPATHI., 2014. Spatial Monitoring of Urban Growth of Nagpur City (India) Using Geospatial Techniques. Journal of Settlements and Spatial Planning, vol. 5, no. 2 (2014) 91-98

16. Stevens D, Dragicevic S, Rothley K. iCity: A GIS-CA modelling tool for urban planning and decision making. Environmental Modelling \& Software. 2007;22(6):76173.

17. Wu Q, Li H-q, Wang R-s, Paulussen J, He Y, Wang M, et al. Monitoring and predicting land use change in Beijing using remote sensing and GIS. Landscape and Urban Planning. 2006;78(4):322-33.

18. Hu Z, Lo CP. Modeling urban growth in Atlanta using logistic regression. Computers, Environment and Urban Systems. 2007;31(6):667-88.

19. Xian G, Crane M, Su J. An analysis of urban development and its environmental impact on the Tampa Bay watershed. Journal of Environmental Management. 2007;85(4):965-76.

20. Liu X, Li X, Shi X, Wu S, Liu T. Simulating complex urban development using kernel-based non-linear cellular automata. Ecological Modelling. 2008;211(1-2):16981.

21. Ayodeji Opeyemi, Z., 2006. Change detection in land use and land cover using remote sensing data and GIS (A case study of Ilorin and its environs in Kwara state). M.Sc. dissertation. Department of Geography, Ibadan University.

22. Asgharpour, M.j., 2004. Multiple Criteria Decision Making. Tehran University Printing and Publication Institute, Tehran, Iran 